\title{
Ferromagnetism in polynuclear systems based on non-linear [MnII2MnIII] building blocks
}

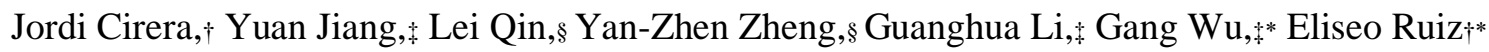

† Departament de Química Inorgànica i Orgànica and Institut de Química Teòrica i Computacional, Universitat de Barcelona, Diagonal 645, 08028 Barcelona, Spain.

\$ State Key Laboratory of Inorganic Synthesis \& Preparative Chemistry, Jilin University, 2699 Qianjin Street, Changchun 130012, China

$\S C e n t r e$ for Applied Chemical Research, Frontier Institute of Science and Technology, Xi'an Jiaotong University, Xi'an 710054, China

\begin{abstract}
The design of new polynuclear transition metal complexes showing large total spin values through parallel alignment of the spins is an important challenge due to the scarcity of bridging ligands that provide with ferromagnetic coupling. Herein, we report two new complexes, a [Mn4IIMn2III]system containing two non-linear [MnII2MnIII] units, and a 1D chain system with [MnII2MnIII] units that are assembled through dicyanamide bridging ligands coordinated to one of the terminal MnII centers. In both cases, the main exchange interaction is that corresponding to the MnII $\cdots$ MnIII, showing a relatively strong ferromagnetic coupling. Density functional theory calculations corroborate such ferromagnetic interactions and also provide one magnetostructural correlation, showing that larger MnII-O-MniII angles enhance the strength of the ferromagnetic coupling. Thus, the non-linear [MniI2MnIII] units present in these two complexes are specially suited because of their larger MnIIO-MnIII angles compared to similar previously reported systems containing linear [MnII2MnIII] unit.
\end{abstract}

Keywords: Single-Molecule Magnets, Density Functional Theory, Exchange Interactions, Magnetic Anisotropy. Magnetostructural correlations 


\section{Introduction}

During the last decades the field of Molecular Magnetism had an important challenge since the discovery in 1993 of single-molecule magnet (SMM) behaviour by Gatteschi and co-workers1 in an Mn12 compound. At very low temperature, individual molecules of such systems behave like magnets, and many research groups have intensively searched for new molecules displaying such an appealing property.2 However, the possible application of such systems has been always circumvented for the requirement of very low temperatures. In such systems, the splitting of $\mathrm{Ms}_{\mathrm{s}}$ states is due to the zero-field splitting phenomenon (ZFS) caused by spin-orbit contributions and the energy difference between the highest and the lowest $\mathrm{M}_{\mathrm{s}}$ states is an energy barrier ( $U_{\text {eff }}$, whose height is directly related with the square of the total spin $(S)$ of the molecule and its magnetic axial anisotropy $(D)$. Thus, such energy barrier must be overcome in order to change the spin direction (from $+\mathrm{M}_{\mathrm{s}}$ to $-\mathrm{M}_{\mathrm{s}}$ states). Also, spin flip processes can occur through quantum tunnelling mechanisms. In order to achieve barriers that difficult the change in the spin direction, large negative $D$ values are required, although for systems with half-integer $\mathrm{S}$ values this term can be positive. Slow relaxation of the magnetization at low temperature is responsible for the presence of a hysteresis loop in magnetization curves, which also display some irregular shapes due to the presence of thermally assisted quantum tunnelling to cross the energy barrier. 3,4 These tunnelling effects are also directly related to the magnitude of the magnetic rhombic anisotropy $(E)$. In order to improve the magnetic properties, it is also mandatory to look for systems with large total spin $S$ value. Logically, in polynuclear complexes the best option is the presence of ferromagnetic coupling between the paramagnetic centres, which would lead to a parallel alignment of the spins, resulting in a large total $S$ value. However, there is a lack of systems showing ferromagnetic coupling, and most commonly exchange interaction pathways in this kind of transition metal complexes are found to be antiferromagnetic. Herein, we report an experimental and theoretical study in a family of polynuclear complexes containing [MnII2MnIII] units, showing ferromagnetic 
coupling between the MnII-MnIII centres. The combination of the MnII and MnIII centres is extremely useful because both cations have relatively large $S$ values, $5 / 2$ and 2 respectively, and they often present ferromagnetic coupling, as has been reported in the Mn19 complex, with a total $S$ $=83 / 2.5,6$ Furthermore, The $\mathrm{d} 4$ configuration of the pseudo-octahedral MnIII cations is a source of magnetic anisotropy.2 Recently, some of us have reported ferromagnetic properties in two linear systems: a discrete $\mathrm{Mn} 3$ complex, $\left[\mathrm{Mn}_{3}(\mathrm{HL})_{2}\left(\mathrm{CH}_{3} \mathrm{OH}\right)_{6}(\mathrm{Br})_{4}\right] \cdot \mathrm{Br} \cdot\left(\mathrm{CH}_{3} \mathrm{OH}\right)_{2}(\mathbf{1}, \mathrm{H} 2 \mathrm{~L}=2-[(9 \mathrm{H}-$ fluoren-9-yl)amino]propane-1,3-diol) and $\quad\left[\mathrm{Mn}_{3}(\mathrm{HL})_{2}\left(\mathrm{CH}_{3} \mathrm{OH}\right)_{2}(\mathrm{Br})_{4}\left(\mathrm{~N}_{3}\right)\left(\mathrm{H}_{2} \mathrm{O}\right)\right] \cdot \mathrm{CH}_{3} \mathrm{OH}$ adopting a 1D chain structure.7 Hence, one of the goals in this work is to provide with a comparison of the magnetic properties between such systems a those showing a distortion that causes a bend in the [Mnıг2MnIII] unit, explaining why such distortion produce an strengthening of the ferromagnetic coupling.

\section{Experimental Section}

\section{Materials and Methods}

Elemental analysis (C, H, and N) was carried out on a Perkin-Elmer 2400 Elemental Analysis. Single-crystal X-ray diffraction measurements of both compounds were carried out on a RigakuRAPID diffractometer equipped with graphite-monchromatic $\operatorname{MoK} \alpha$ radiation $(\lambda=0.71073 \AA)$. Absorption corrections were applied by using SADABS. The structures of $\mathbf{3}$ and $\mathbf{4}$ were solved by direct methods and refined by full-matrix least-squares techniques based on $F_{2}$ using the SHELXS97 program. All the non-hydrogen atoms were refined with anisotropic parameters. Crystallographic data have been deposited with the Cambridge Crystallographic Data Centre: CCDC 1482230 for 3 and 1482219 for $\mathbf{4}$. The magnetic measurements were carried out with a Quantum Design MPMS-XL7 SQUID magnetometer using polycrystalline sample. Magnetic susceptibility data were conducted from 300 to $2 \mathrm{~K}$ at various DC field and field-dependant magnetization plots were also performed for applied fields ranging from 0 to $7 \mathrm{~T}$ at indicated 
temperatures. The AC susceptibility measurements were conducted with an oscillating AC field of 3 Oe at various AC frequencies at 0 Oe and 1000 Oe DC fields. Diamagnetic correction has been calculated from Pascal constants and the background of sample holder was also subtracted.

Table 1 Crystallographic data for 3 and $\mathbf{4}$.

\begin{tabular}{lll} 
Compound & \multicolumn{2}{c}{$\mathbf{3}$} \\
\hline Molecular Formula & $\mathrm{C}_{78} \mathrm{H}_{108} \mathrm{O}_{16} \mathrm{~N}_{4} \mathrm{Mn}_{6} \mathrm{Cl}_{10} 0$ & $\mathrm{C}_{39} \mathrm{H}_{47} \mathrm{~N}_{6} \mathrm{O}_{7} \mathrm{Mn}_{3} \mathrm{Cl}_{4}$ \\
Fw (g mol-1) & 2041.82 & 1018.45 \\
Crystal system & Monoclinic & Monoclinic \\
Space group & $P 2(1) / \mathrm{n}$ & $P 2(1) / \mathrm{n}$ \\
$a(\AA)$ & $19.121(4)$ & $14.157(3)$ \\
$b(\AA)$ & $12.396(3)$ & $12.201(2)$ \\
$c(\AA)$ & $20.085(4)$ & $27.433(6)$ \\
$\alpha($ deg$)$ & 90.00 & 90.00 \\
$\beta($ deg $)$ & $96.26(3)$ & $101.37(3)$ \\
$\gamma($ deg) & 90.00 & 90.00 \\
$V(\AA 3)$ & $4732.3(16)$ & $4645.2(16)$ \\
$Z$ & 2 & 2 \\
$D($ calcd, g cm-3) & 1.433 & 1.456 \\
$\mu(\mathrm{mm}-1)$ & 1.118 & 1.085 \\
$F(000)$ & 2104 & 2088 \\
Goodness-of-fit on $F_{2}, S$ & 1.085 & 1.100 \\
$R 1, w R 2[I \geq 2 \sigma(I)]$ & $0.0731,0.1107$ & $0.0695,0.1095$ \\
$R 1, w R 2$ [all data] & $0.2006,0.2191$ & $0.1816,0.1978$ \\
\hline
\end{tabular}

\section{Synthesis}

For the synthetic details of compounds $\mathbf{1}$ and 2, please see ref 7 .

Preparation of $\mathrm{Mn}_{6}(\mathrm{HL}) 4\left(\mathrm{CH}_{3} \mathrm{OH}\right)_{6}(\mathrm{Cl})_{10} \cdot\left(\mathrm{Et}_{2} \mathrm{O}\right)_{2}(\mathbf{3})$ :

A solution of $\mathrm{MnCl}_{2} \cdot 4 \mathrm{H}_{2} \mathrm{O}(0.18 \mathrm{~g}, 0.6 \mathrm{mmol})$ in $\mathrm{CH}_{3} \mathrm{OH}(5 \mathrm{~mL})$ was added with stirring to a solution of $\mathrm{H}_{2} \mathrm{~L}(0.1 \mathrm{~g}, 0.4 \mathrm{mmol})$ in $\mathrm{CH}_{3} \mathrm{CN}(5 \mathrm{~mL})$. After the mixture had been stirred for $1 \mathrm{~h}$, the yellow-brown suspension was filtered, and the filtrate was layered by hexane/Et $2 \mathrm{O}(1: 1)$. After 6 days, yellow prism crystals were obtained in c.a. $40 \%$ yield (based on Mn). Elemental analysis (\%) Calcd for $\mathrm{Mn}_{6}(\mathrm{HL})_{4}\left(\mathrm{CH}_{3} \mathrm{OH}\right)_{6}(\mathrm{Cl})_{10} \cdot\left(\mathrm{Et}_{2} \mathrm{O}\right)_{2}\left(\mathrm{C}_{78} \mathrm{H}_{108} \mathrm{O}_{16} \mathrm{~N}_{4} \mathrm{Mn}_{6} \mathrm{Cl}_{10}\right): \mathrm{C} 45.88, \mathrm{H}$ 5.33, N 2.74; found: C 45.09, H 5.12, N 2.89. 


\section{Preparation of $\mathrm{Mn}_{3}(\mathrm{HL})_{2}\left(\mathrm{CH}_{3} \mathrm{OH}\right)_{3}(\mathrm{Cl})_{4}(\mathrm{dca}) \cdot \mathrm{CH}_{3} \mathrm{CN}(4)$ :}

A solution of Nadca $(0.02 \mathrm{~g}, 0.2 \mathrm{mmol})$ in $\mathrm{CH}_{3} \mathrm{OH}(5 \mathrm{~mL})$ was added with stirring to a solution of $\mathrm{MnCl}_{2} 4 \mathrm{H}_{2} \mathrm{O}(0.18 \mathrm{~g}, 0.6 \mathrm{mmol})$ and $\mathrm{H}_{2} \mathrm{~L}(0.1 \mathrm{~g}, 0.4 \mathrm{mmol})$ in $\mathrm{CH}_{3} \mathrm{CN}(5 \mathrm{~mL})$. After the mixture had been stirred for $1 \mathrm{~h}$, the yellow-brown suspension was filtered, and the filtrate was layered by hexane/Et2O (1:1). After 4 days, light yellow prism crystals were obtained in c.a. $40 \%$ yield (based on $\mathrm{Mn})$. Elemental analysis (\%) Calcd for $\mathrm{Mn}_{3}(\mathrm{HL})_{2}\left(\mathrm{CH}_{3} \mathrm{OH}\right)_{3}(\mathrm{Cl})_{4}(\mathrm{dca}) \cdot \mathrm{CH}_{3} \mathrm{CN}$ $\left(\mathrm{C}_{39} \mathrm{H}_{47} \mathrm{~N}_{6} \mathrm{O}_{7} \mathrm{Mn}_{3} \mathrm{Cl}_{4}\right): \mathrm{C} 45.99, \mathrm{H} 4.65, \mathrm{~N}$ 8.25; found: C 46.23, H 4.08, N 8.33.

\section{Computational details}

To calculate the exchange interactions,8-10 a phenomenological Heisenberg Hamiltonian was used, excluding the terms relating to magnetic anisotropy ( $D$ and $E$ zero-field splitting parameters), to describe the exchange coupling in the polynuclear complex.

$$
\hat{H}=\underset{a<b}{J} \hat{S}_{a} \hat{S}_{a}
$$

where $\hat{S}_{a}$ and $\hat{S}_{b}$ are the spin operators of the different paramagnetic centres. The $J_{a b}$ parameters are the pairwise coupling constants between the paramagnetic centres of the molecule. Basically, we need to calculate the energy of $n+1$ spin distributions for a system with $n$ different exchange coupling constants. In our particular case, 3 calculations were done for system 1, 4 calculations for system 4 and 11 calculations for system 3 . For the system $\mathbf{1}$, they correspond to the high-spin $S_{z}=7$ solution, one $S=3$ wave function flipping the spin of the central MnIII atom and one $S=2$ solution corresponding to the spin inversion of the terminal MnII atom. For system $\mathbf{4}$, they correspond to the high-spin $S_{z}=7$ solution, one $S=3$ wave function flipping the spin of the central MnIII atom and two $S=2$ solutions corresponding to the spin inversion of each of the terminals MnII atoms. For system 3, the eleven spin distributions correspond to the high-spin $S_{z}=14$ solution, two $S=10$ solutions corresponding to the spin inversion of only one MnIII centre, two $S=9$ solutions corresponding to the spin inversion of only one MnII centre, one $S=6$ solution corresponding to the 
spin inversion of all the MnIII centres, two $S=4$ solutions corresponding to the spin inversion of the two terminal MnII centres or the two central MnII centres, and three $S=0$ solutions corresponding to the spin inversion of the first three metal centres, the last three metal centres or the spin inversion of the second, fourth and sixth metal centres (see Table S1). These energy values allow us to build up a system of $n$ equations in which the $\mathrm{J}$ values are the unknowns. Gaussian0311 calculations were performed with the hybrid B3LYP functional12 using a guess function generated with the help of the fragments option which employs a procedure that allows us to determine individually the local charges and multiplicities of the atoms. A triple- $\xi$ all-electron Gaussian basis set13 was used for all the atoms. The same approach is valid for large polynuclear complexes, for instance a $\mathrm{Fe}_{42}$ system 14 or dinuclear complexes with very large bridging ligands. 15

\section{Results and Discussion}

Crystal structure of the $\left[\mathrm{Mn}_{2}{ }_{2} \mathrm{Mn}^{\mathrm{III}}\right]$ cores in $\mathrm{Mn}_{3}(\mathrm{HL})_{2}\left(\mathrm{CH}_{3} \mathrm{OH}\right)_{6}(\mathrm{Br})_{4} \cdot \mathrm{Br} \cdot\left(\mathrm{CH}_{3} \mathrm{OH}\right)_{2}$ (1) and $\mathrm{Mn}_{3}(\mathrm{HL})_{2}\left(\mathrm{CH}_{3} \mathrm{OH}\right)_{2}(\mathrm{Br})_{4}\left(\mathrm{~N}_{3}\right)\left(\mathrm{H}_{2} \mathrm{O}\right) \cdot \mathrm{CH}_{3} \mathrm{OH}(\mathbf{2})$
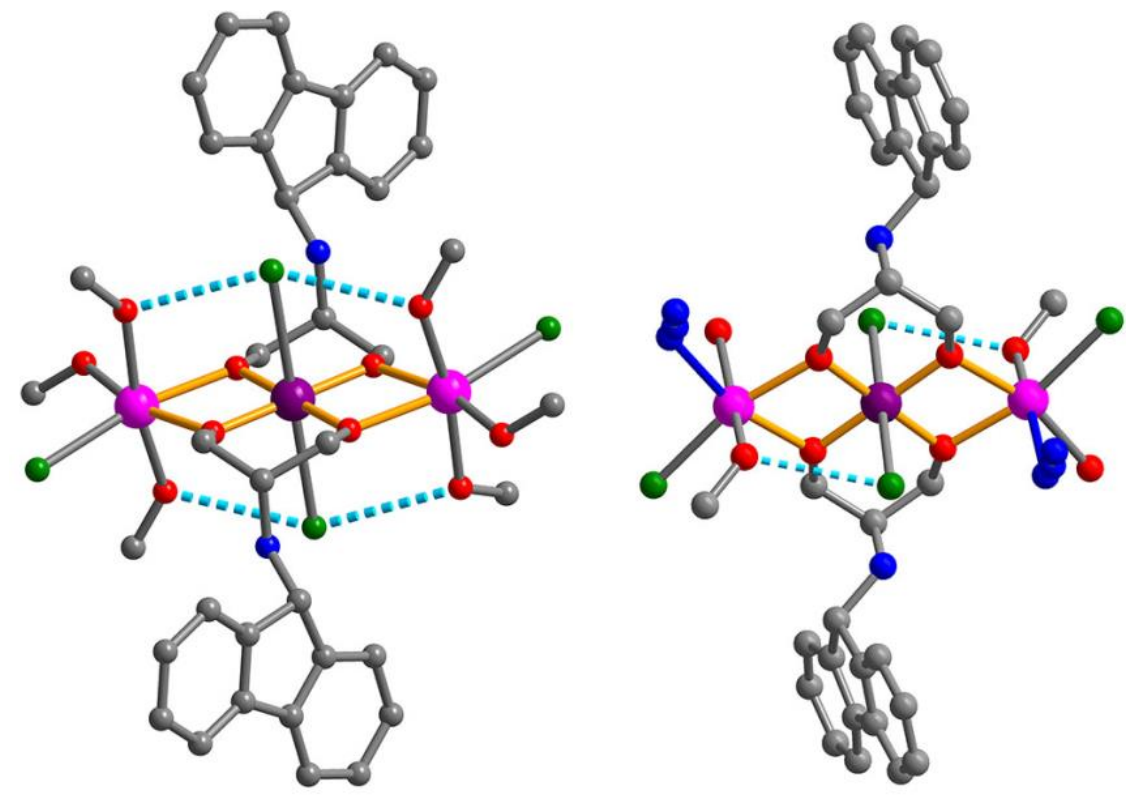

Fig. 1 Crystal structure of the linear $\left[\mathrm{Mn}_{2}^{\mathrm{II}} \mathrm{Mn}^{\mathrm{III}}\right]$ units in 1 (left) and 2 (right). Light blue dashed lines highlight intratrinuclear H-bonds. (C: grey, $\mathrm{Mn}^{\mathrm{II}}$ : pink, $\mathrm{Mn}^{\mathrm{III}}$ : purple; O: red; Br: green; $\mathrm{N}$ : blue; $\mathrm{H}$ atoms and guest molecules are omitted for clarity). 
The $\left[\mathrm{Mn}_{2}^{\mathrm{II}}{ }_{2} \mathrm{Mn}^{\mathrm{III}}\right]$ cores in $\mathbf{1}$ and $\mathbf{2}$ are quite similar (see Fig. 1). ${ }^{7}$ The main difference between these two motifs is the intra-molecular $\mathrm{H}$-bonds pattern; in $\mathbf{1}$ the two central $\mathrm{Br}^{-}$ ions form cyclic $\mathrm{H}$-bonds with four lateral $\mathrm{CH}_{3} \mathrm{OH}$ molecules while in 2 the central $\mathrm{Br}^{-}$ions only connect with two of the lateral $\mathrm{CH}_{3} \mathrm{OH}$ with $\mathrm{H}$-bonding. Note that in both compounds, the $\mathrm{Mn}^{\mathrm{II}}-\mathrm{Mn}^{\mathrm{III}}-\mathrm{Mn}^{\mathrm{II}}$ angles are $180^{\circ}$, indicating linear $\left[\mathrm{Mn}^{\mathrm{II}}{ }_{2} \mathrm{Mn}^{\mathrm{III}}\right]$ aggregates.

Crystal structure of $\mathrm{Mn}_{6}(\mathrm{HL})_{4}\left(\mathrm{CH}_{3} \mathrm{OH}\right)_{6}(\mathrm{Cl})_{10} \bullet\left(\mathrm{Et}_{2} \mathrm{O}\right)_{2}(3)$

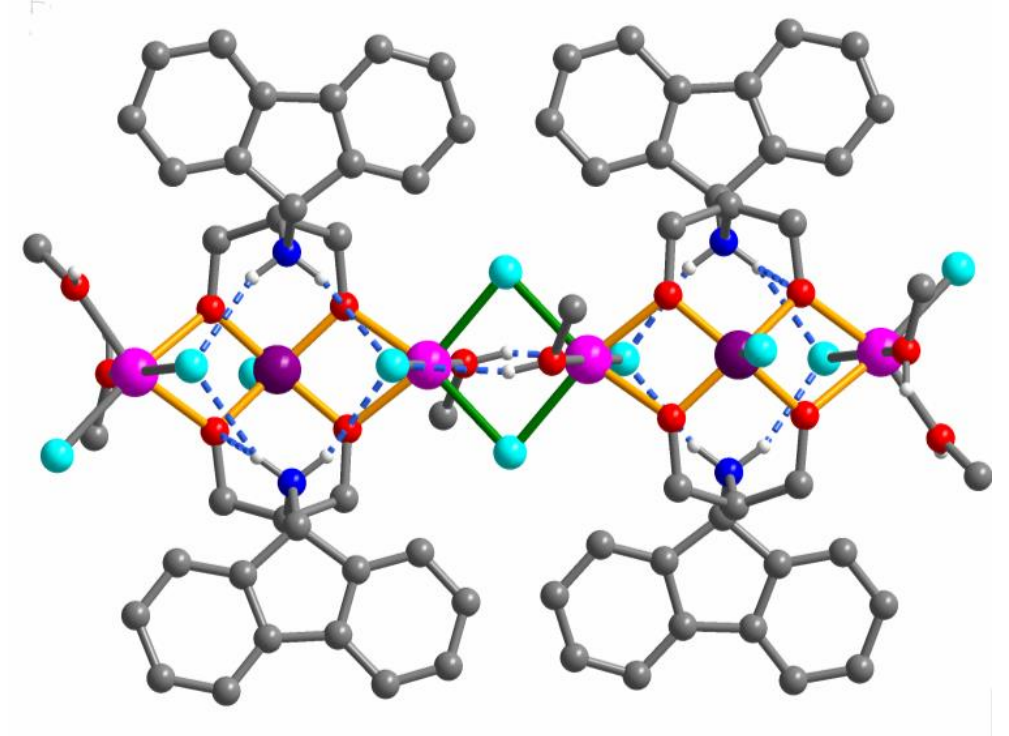

Fig. 2 Crystal structure of $\left[\mathrm{Mn}_{2}^{\mathrm{II}} \mathrm{Mn}^{\mathrm{III}}\right]$ dimer in 3. Light blue dashed lines highlight intramolecular H-bonds. (C: grey, $\mathrm{Mn}^{\mathrm{II}}$ : pink, $\mathrm{Mn}^{\mathrm{III}}$ : purple; $\mathrm{O}$ : red; $\mathrm{Cl}$ : light blue; $\mathrm{N}$ : deep blue; Carbon $\mathrm{H}$ atoms and guest molecules are omitted for clarity).

Single-crystal X-ray diffraction analysis reveals that compound 3 crystalize in the $P 2(1) / \mathrm{n}$ monoclinic space group. Compound 3 can be viewed as a dimer of two $\left[\mathrm{Mn}^{\mathrm{II}}{ }_{2} \mathrm{Mn}^{\mathrm{III}}\right]$ units linked by double $\mathrm{Cl}^{-}$bridges (Fig. 2). Unlike the octahedrally coordinated $\mathrm{Mn}^{\mathrm{III}}$ in $\mathbf{1}$ and $\mathbf{2}$, the central $\mathrm{Mn}^{\mathrm{III}}$ in $\mathbf{3}$ is five-coordinated to four oxygen atoms from diol ligands and only one $\mathrm{Cl}^{-}$ion. The protonated $\mathrm{NH}_{2}{ }^{+}$groups of the diol ligand $\mathrm{H}$-bonded to terminal $\mathrm{Cl}^{-}$ion of $\mathrm{Mn}^{\mathrm{II}}$, forming a cyclic pattern. For optimized $\mathrm{Cl}-\mathrm{N}$ distance and $\mathrm{NH}-\mathrm{Cl}$ angle, the $\left[\mathrm{Mn}_{2}{ }_{2} \mathrm{Mn}^{\mathrm{III}}\right]$ motif in 3 is forced to twist a little bit with the $\mathrm{Mn}^{\mathrm{II}}-\mathrm{Mn}^{\mathrm{III}}-\mathrm{Mn}^{\mathrm{II}}$ angle of 
$145.00^{\circ}$. However, in $\mathbf{1}$ and $\mathbf{2}$, the $\left[\mathrm{Mn}^{\mathrm{II}}{ }_{2} \mathrm{Mn}^{\mathrm{III}}\right]$ motif is linear. We hypothesis that such charge-assistant $\mathrm{H}$-bonds, which is much stronger than the neutral ones observed in compound $\mathbf{1}$ and $\mathbf{2}$, is the driving force that bends the linear $\left[\mathrm{Mn}^{\mathrm{II}}{ }_{2} \mathrm{Mn}^{\mathrm{III}}\right]$ motif into angular one. Also the $\mathrm{Cl}^{-}$ion form relatively weak $\mathrm{H}$-bond with terminal $\mathrm{CH}_{3} \mathrm{OH}$ from adjust $\mathrm{Mn}^{\mathrm{II}}$ ions. It is interesting to note that a small difference in radius between $\mathrm{Cl}^{-}$and $\mathrm{Br}^{-}$ions could have such big impact on the structure of the metal-ligand core. Although coming through a linear to angular structural deformation, it should be noted that the $\mathrm{Mn}^{\mathrm{II}}-\mathrm{Mn}^{\mathrm{III}}$ distance and $\mathrm{Mn}^{\mathrm{II}}-\mathrm{O}-\mathrm{Mn}^{\mathrm{III}}$ angles are very similar in compounds $\mathbf{1}, \mathbf{2}$, and $\mathbf{3}$.

Crystal structure of $\mathrm{Mn}_{3}(\mathrm{HL})_{2}\left(\mathrm{CH}_{3} \mathrm{OH}\right)_{3}(\mathrm{Cl})_{4}(\mathrm{dca}) \cdot \mathrm{CH}_{3} \mathrm{CN}(4)$

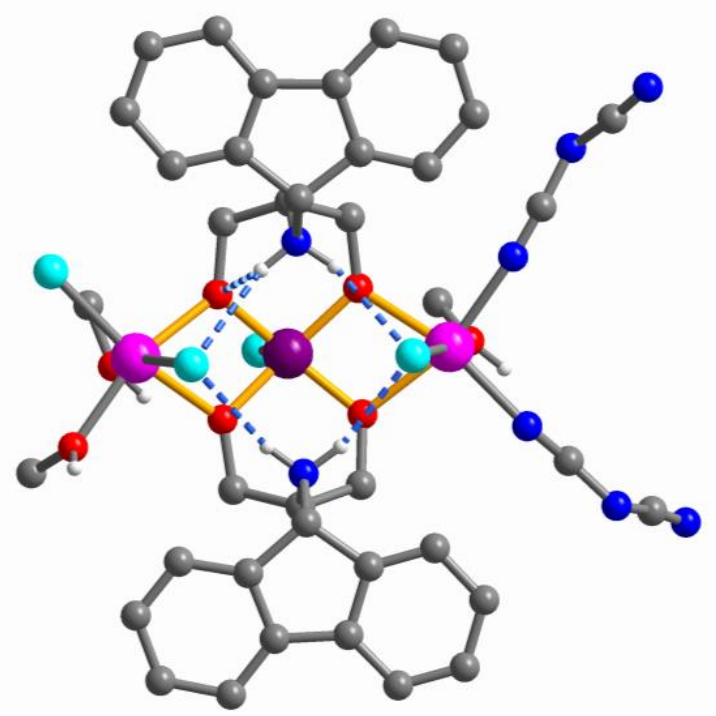

Fig. 3 Crystal structure of the non-linear $\left[\mathrm{Mn}^{\mathrm{II}}{ }_{2} \mathrm{Mn}^{\mathrm{III}}\right]$ unit in 4. Light blue dashed lines highlight intramolecular H-bonds. (C: grey, $\mathrm{Mn}^{\mathrm{II}}$ : pink, $\mathrm{Mn}^{\mathrm{III}}$ : purple; $\mathrm{O}$ : red; $\mathrm{Cl}$ : light blue; $\mathrm{N}$ : deep blue; Carbon $\mathrm{H}$ atoms and guest molecules are omitted for clarity).

Compound 4 crystalize in the $P 2(1) / \mathrm{n}$ monoclinic space group. The asymmetric unit of $\mathbf{4}$ is shown in Fig. 3. Similar to compound 3, the $\left[\mathrm{Mn}^{\mathrm{II}}{ }_{2} \mathrm{Mn}^{\mathrm{III}}\right]$ motif in 4 is twisted with the $\mathrm{Mn}^{\mathrm{II}}$ $\mathrm{Mn}^{\mathrm{III}}-\mathrm{Mn}^{\mathrm{II}}$ angle of $149.12^{\circ}$. The intramolecular H-bond pattern is also very similar to compound 3, indicating good structural stability of the angular $\left[\mathrm{Mn}^{\mathrm{II}}{ }_{2} \mathrm{Mn}^{\mathrm{III}}\right]$ building during 
self assemble process. The [ $\left.\mathrm{Mn}^{\mathrm{III}} \mathrm{Mn}^{\mathrm{II}}{ }_{2}\right]$ units are further linked together through dca bridges (Fig. S1); forming a helical chain of [Mn $\left.{ }^{\mathrm{II}}-\mathrm{NC}-\mathrm{N}-\mathrm{CN}-\mathrm{Mn}^{\mathrm{II}}\right]$.

\section{Magnetic Properties}

Temperature-dependent magnetic susceptibility data of $\mathbf{3}$ was measured between 2 and 300K under 1000 Oe DC field on polycrystalline samples (Fig. 4). At room temperature, the $\chi T$ product is $27.61 \mathrm{~cm}^{3} \mathrm{~K} \mathrm{~mol}^{-1}$, which is higher than the theoretical spin-only values for $\left[\mathrm{Mn}^{\mathrm{II}}{ }_{4} \mathrm{Mn}^{\mathrm{III}}{ }_{2}\right]$ units $\left(23.5 \mathrm{~cm}^{3} \mathrm{~K} \mathrm{~mol}^{-1}\right.$ with $S_{\mathrm{Mn}(\mathrm{III})}=2, S_{\mathrm{Mn}(\mathrm{II})}=5 / 2$ and $\left.g_{\mathrm{Mn}(\mathrm{III})}=g_{\mathrm{Mn}(\mathrm{II})}=2\right)$, indicating dominant intramolecular ferromagnetic interactions in the system. Upon cooling, $\chi T$ increases gradually and exhibits a broad peak with a maximum of $37.13 \mathrm{~cm}^{3} \mathrm{~K} \mathrm{~mol}^{-1}$ at $26 \mathrm{~K}$ for 3. The further decrease of $\chi T$ below the peak may be ascribed to the intermolecular and/or partially intramolecular antiferromagnetic interactions (this second option will be corroborated in the next section by DFT calculations) with the value of $12.18 \mathrm{~cm}^{3} \mathrm{~K} \mathrm{~mol}^{-1}$ at $2 \mathrm{~K}$. Based on the structure and symmetry, the magnetic susceptibility was also fitted. For 3, a $\left[\mathrm{Mn}_{2}^{\mathrm{II}} \mathrm{Mn}^{\mathrm{III}}\right]$ dimer linked by chloride anions, two magnetic interaction parameters were used based on the following Hamiltonian:

$$
\hat{H}=J_{a}\left(\hat{S}_{1} \hat{S}_{2}+\hat{S}_{2} \hat{S}_{3}+\hat{S}_{4} \hat{S}_{5}+\hat{S}_{5} \hat{S}_{6}\right) \quad J_{b} \hat{S}_{3} \hat{S}_{4}
$$

where $J_{\mathrm{a}}$ is the $\mathrm{Mn}^{\mathrm{II}} \cdots \mathrm{Mn}^{\mathrm{III}}$ and $J_{\mathrm{b}}$ is the $\mathrm{Mn}^{\mathrm{II}} \cdots \mathrm{Mn}^{\mathrm{II}}$ magnetic interactions within the $\left[\mathrm{Mn}_{4}{ }_{4} \mathrm{Mn}^{\mathrm{III}}{ }_{2}\right]$ unit. The best fitting affords $J_{\mathrm{a}}=8.0(4) \mathrm{cm}^{-1}, J_{\mathrm{b}}=-2.4(2) \mathrm{cm}^{-1}, g=2.02(1)$. This confirms the decrease of $\chi T$ plots at low temperature spans originates from the antiferromagnetic interactions between two ferromagnetically-coupled $\mathrm{S}=7 \quad\left[\mathrm{Mn}^{\mathrm{II}}{ }_{2} \mathrm{Mn}^{\mathrm{III}}\right]$ units. The susceptibilities at low temperature span at various DC fields were also performed, where it can be seen that the magnetic susceptibility is dependent with the external field. With field increases, the peak around $5 \mathrm{~K}$ reduces firstly and then keeps rough constant till to $5000 \mathrm{Oe}$, suggesting a possible spin-flop behaviour in the system. This indicates a 
transition from antiferromagnetic state to spin-flop state. ${ }^{16}$ The tail at very low temperature may originate from the trace paramagnetic impurities. In order to confirm the spin-flop behaviour, field-dependent magnetization plots were also displayed from 2 to $5 \mathrm{~K}$. The magnetizations show a little $S$-shaped behaviour and the magnetization tends to saturate at higher field, especially at $2 \mathrm{~K}$. This phenomenon agrees well with the spin-flop behaviour when the field is higher the critical field that a ferromagnetic state would emerge (Fig. 5a). Magnetic hysteresis was also observed at $2 \mathrm{~K}$ with coercive field about $50 \mathrm{Oe}$ (Fig. 5b). AC susceptibility measurements at 0 Oe DC field was also performed. The real and imaginary plots show peaks at around $5 \mathrm{~K}$ with no frequency dependence of signals, implying the existence of antiferromagnetic ordering at about $5 \mathrm{~K}$ (Fig. 6). In order to confirm this magnetic ordering, the temperature dependencies of field-cooled (FC) and zero-field-cooled (ZFC) magnetizations were also displayed under a 100 Oe field upon warming from $2 \mathrm{~K}$. The FC and ZFC plots present a disagreement below $\sim 5 \mathrm{~K}$, suggesting again the onset of the long range antiferromagnetic ordering (Fig. 7).
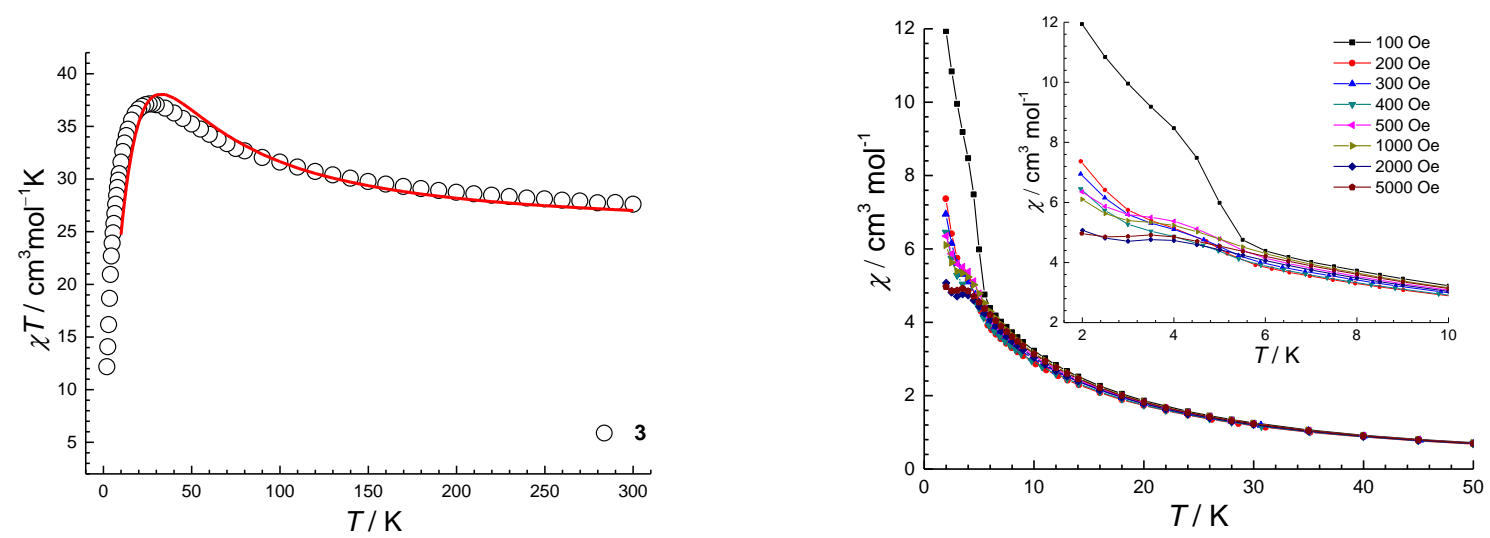

Fig. 4 (a) $\chi T$ vs. $T$ plot under 1000 Oe DC field for 3. The red lines represent the fitting curves, details see text. (b) Thermal variation of the molar susceptibility for $\mathbf{3}$ at different applied fields. 

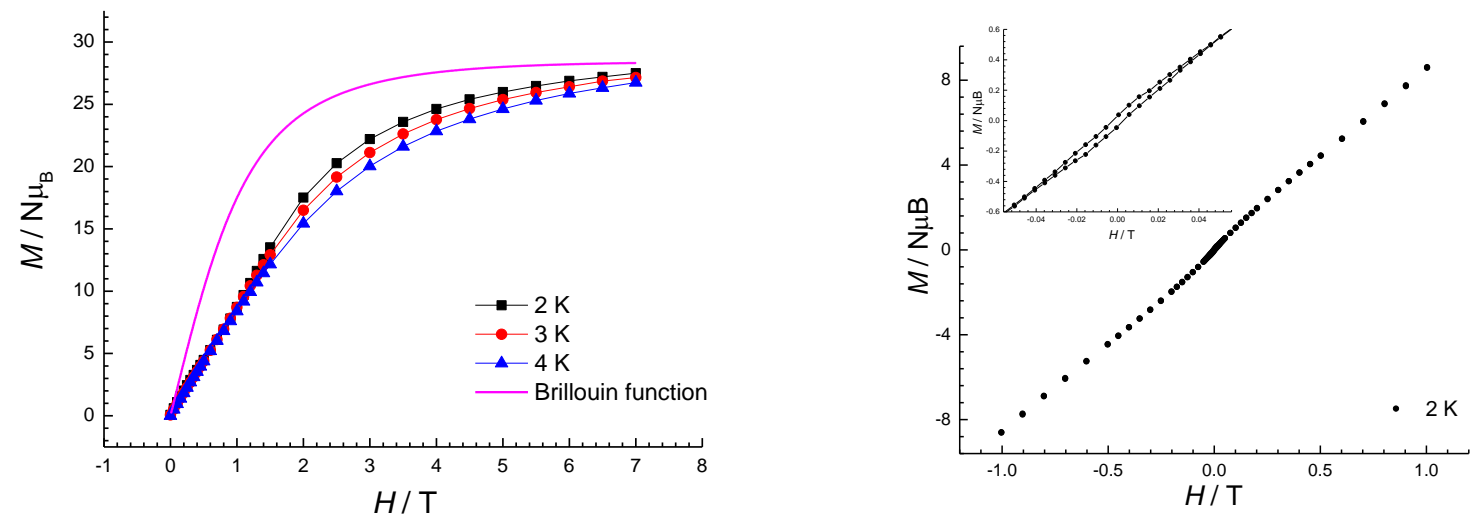

Fig. 5 (a) Field-dependent magnetization plots at indicated temperatures. The pink line is

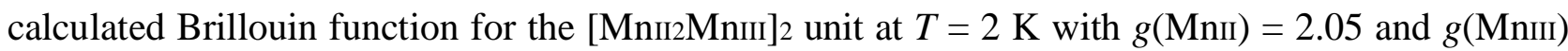
$=1.98$. (b) Magnetic hysteresis loop for 3 at $2 \mathrm{~K}$. Insert: the enlarged view of the hysteresis plot.
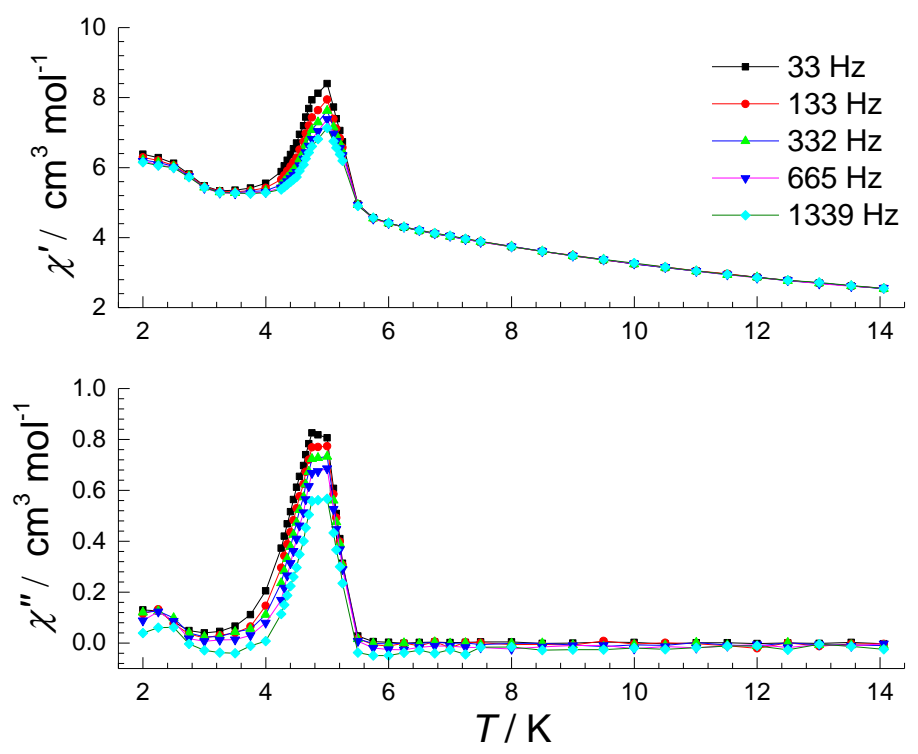

Fig. 6 AC susceptibilities under 0 Oe DC field for 3 at indicated frequencies. 


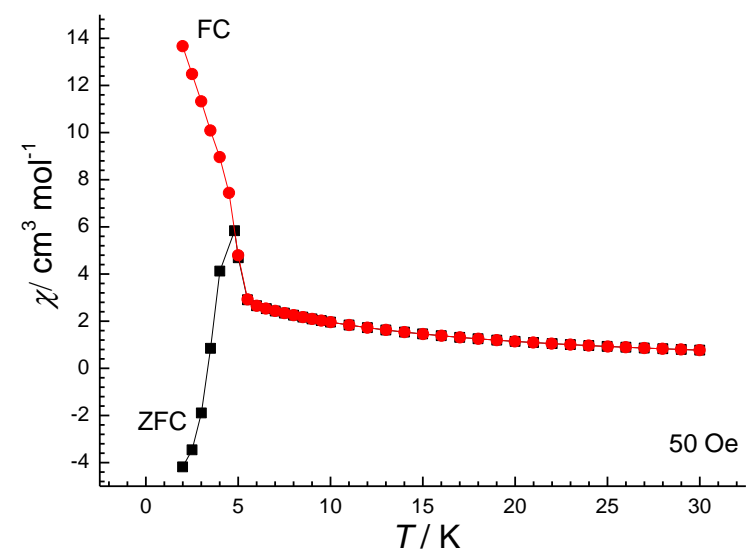

Fig. 7 ZFC and FC magnetization plots of 3 at 50 Oe DC field from 2 to $30 \mathrm{~K}$.

For complex 4, temperature-dependent magnetic susceptibility data was measured between 2 and $300 \mathrm{~K}$ under 1000 Oe DC field (Fig. 8a). At room temperature, the $\chi T$ product is 15.08 $\mathrm{cm}^{3} \mathrm{~K} \mathrm{~mol}{ }^{-1}$, which is obviously higher than the theoretical spin-only values for the $\left[\mathrm{Mn}^{\mathrm{II}}{ }_{2} \mathrm{Mn}^{\mathrm{III}}\right]$ units $\left(11.8 \mathrm{~cm}^{3} \mathrm{~K} \mathrm{~mol}^{-1}\right.$ with $S_{\mathrm{Mn}(\mathrm{III})}=2, S_{\mathrm{Mn}(\mathrm{III})}=5 / 2$ and $\left.g_{\mathrm{Mn}(\mathrm{III})}=g_{\mathrm{Mn}(\mathrm{II})}=2\right)$, indicating dominant intramolecular ferromagnetic interactions in the system. With temperature decreases, the $\chi T$ vs. $T$ curve display a similar behaviour compared to 3 . Upon cooling, both $\chi T$ plots increase gradually and exhibit broad peaks with a maximum of 16.80 $\mathrm{cm}^{3} \mathrm{~K} \mathrm{~mol}^{-1}$ at $55 \mathrm{~K}$ for 4 . The further decrease of $\chi T$ below the peaks should be ascribed to the antiferromagnetic interactions between the $\left[\mathrm{Mn}_{2}^{\mathrm{II}} \mathrm{Mn}^{\mathrm{III}}\right]$ units bridged by $d c a$ ligand and/or the adjacent chains, with a value of $8.08 \mathrm{~cm}^{3} \mathrm{~K} \mathrm{~mol}^{-1}$ at $2 \mathrm{~K}$. Based on the basic trimer unit, the magnetic susceptibility was fitted by the following Hamiltonian:

$$
\hat{H}=J_{a}\left(\hat{S}_{1} \hat{S}_{2}+\hat{S}_{2} \hat{S}_{3}\right)
$$

where $J_{a}$ defines the $\mathrm{Mn}^{\mathrm{II}} \cdots \mathrm{Mn}^{\mathrm{III}}$ magnetic interaction within the $\left[\mathrm{Mn}_{2}^{\mathrm{II}}{ }_{2} \mathrm{Mn}^{\mathrm{III}}\right]$ unit. In order to fit the lower temperature data, the interaction between the $\left[\mathrm{Mn}_{2}^{\mathrm{II}} \mathrm{Mn}^{\mathrm{III}}\right]$ units was neglected and regarded it as a molecular field around the trinuclear unit which is described with $z J^{\prime}$. Temperature-independent paramagnetism (TIP) has also been added in the frame of the mean field approximation. ${ }^{17-19}$ The best fitting affords $J / k_{\mathrm{B}}=13.0(1) \mathrm{K}, \mathrm{g}=2.02(7)$, $z J^{\prime} / k_{\mathrm{B}}=-0.34(5) \mathrm{K}$, TIP $=0.0068(4)$. The larger positive $J$ indicates the dominant intramolecular ferromagnetic interactions. Field-dependent magnetization plots were also performed from 2 to $10 \mathrm{~K}$ (Fig. 8b). The magnetizations increase slowly up to $7 \mathrm{~T}$ with a value of $8.20 \mu_{\mathrm{B}}$ at $7 \mathrm{~T}$ at $2 \mathrm{~K}$, which is far from the expected value of $14 \mu_{\mathrm{B}}$ for a 
ferromagnetic coupled $\left[\mathrm{Mn}^{\mathrm{II}}{ }_{2} \mathrm{Mn}^{\mathrm{III}}\right]$ unit. This behaviour is a characteristic of a canted antiferromagnetic ground state possessing a small remnant or spontaneous magnetization resulting from the non-compensation of the two antiferromagnetically coupled magnetic sublattices. AC susceptibility measurements at 0 Oe DC field was also performed. However, no any slow magnetic relaxation behaviour was observed (Fig. S1).
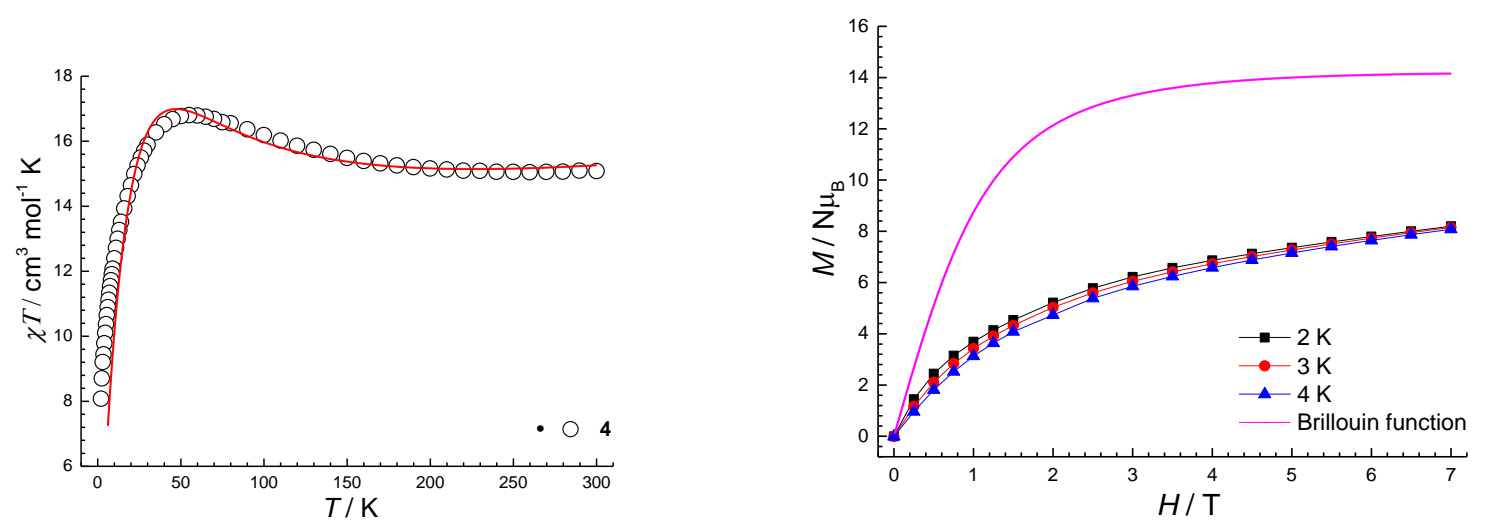

Fig. 8 (a) $\chi T$ vs. $T$ plot under 1000 Oe DC field for 3. The red lines represent the fitting curves, details see text. (b) Field-dependent magnetization plots at indicated temperatures. The pink line is calculated Brillouin function for the $\left[\mathrm{MnII}_{\mathrm{II}} \mathrm{MnIII}\right] 2$ unit at $T=2 \mathrm{~K}$ with $g(\mathrm{MnII})=2.05$ and $g(\mathrm{Mn} I \mathrm{II})$ $=1.98$.

\section{Electronic Structure Calculations}

The intramolecular magnetic interactions in the 1,3 and 4 complexes were studied with a Heisenberg Hamiltonian (see Computational Details section) and the J values calculated are given in Table 2. The complex $\mathbf{1}$ is a discrete linear $\mathrm{Mn}_{3}\left[\mathrm{Mn}_{2}{ }_{2} \mathrm{Mn}^{\mathrm{III}}\right]$ complex, complex $\mathbf{3}$ is a non-linear $\mathrm{Mn}_{6}$ complex with two equivalent $\left[\mathrm{Mn}_{2}^{\mathrm{II}} \mathrm{Mn}^{\mathrm{III}}\right]$ units and 4 is a $1 \mathrm{D}$ chain system with the non-linear $\left[\mathrm{Mn}_{2}{ }_{2} \mathrm{Mn}^{\mathrm{III}}\right]$ units coordinated through dca ligands to extend the dimensionality to $1 \mathrm{D}$ chain (see Figure 9 for the description of the exchange interactions). 
Table 2 DFT Calculated $J$ values (in $\mathrm{cm}-1$ ) for the studied complexes also indicating the parameters relevant for the magnetostructural correlations (distances in $\AA$ and angles in degrees).

\begin{tabular}{lcccc} 
Complex & Bridging ligands & Mn-Mn & Mn-O-Mn & $J_{\text {calc }}$ \\
\hline $\mathbf{1}$ & & & & \\
$J_{1}$ & $2(\mu$-OCR $)$ & 3.23 & 103.0 & +11.8 \\
$J_{2}$ & & 6.45 & & +0.4 \\
\hline $\mathbf{3}$ & & & & \\
$J_{1}$ & $2(\mu$-OCR $)$ & 3.23 & 104.4 & +19.2 \\
$J_{2}$ & $2(\mu$-OCR $)$ & 3.20 & 103.7 & +13.3 \\
$J_{3}$ & $2(\mu$-Cl $)$ & 3.45 & & -9.1 \\
$J_{4}$ & & 6.13 & & +0.2 \\
$J_{5}$ & & 6.65 & & -0.1 \\
\hline $\mathbf{4}$ & & & & \\
$J_{1}$ & $2(\mu$-OCR $)$ & 3.22 & 105.0 & +20.5 \\
$J_{2}$ & $2(\mu$-OCR $)$ & 3.23 & 104.2 & +16.2 \\
$J_{3}$ & & 6.22 & & +0.2 \\
\hline
\end{tabular}



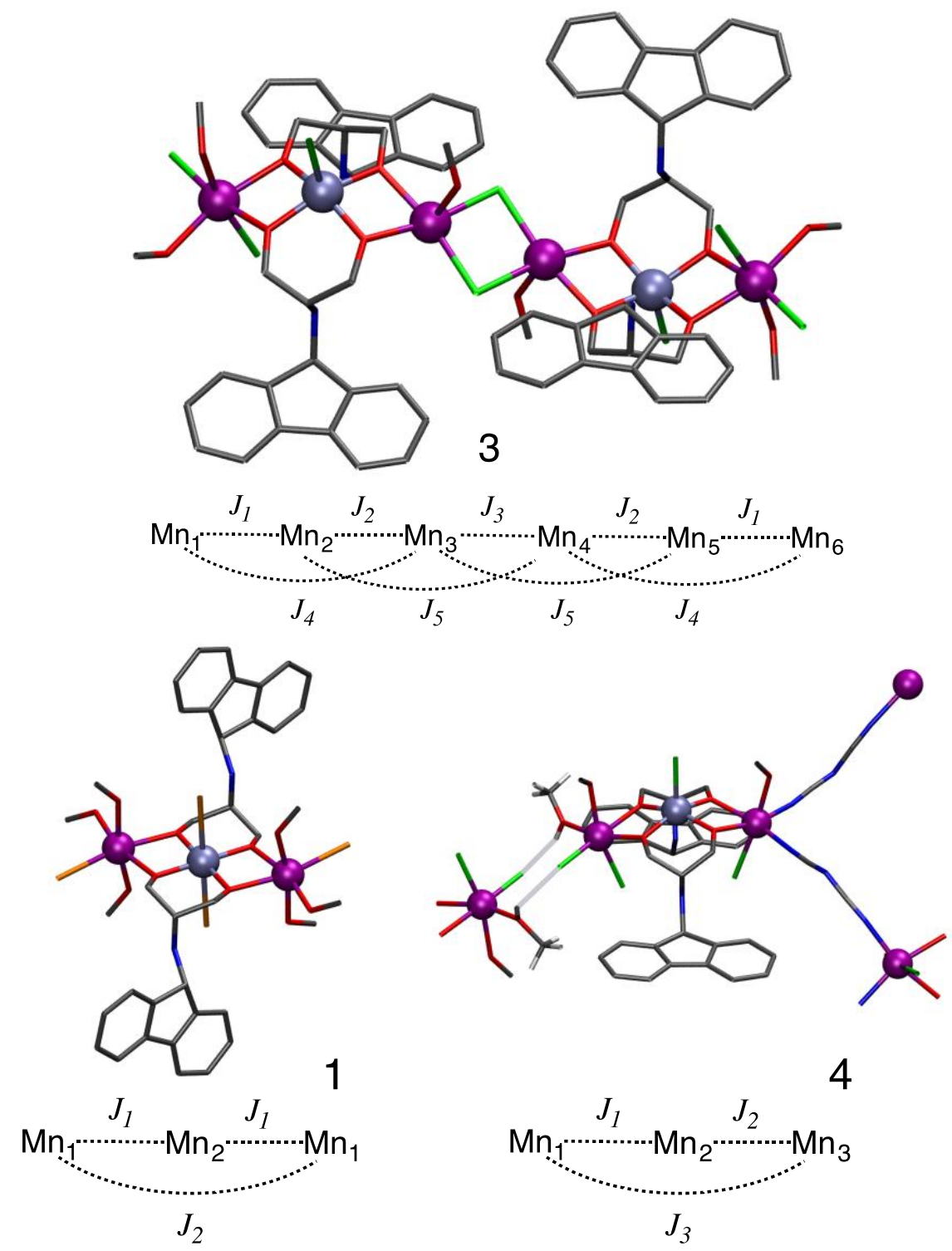

Fig. 9 Topology of the exchange interactions in the compounds 1, 3 and $\mathbf{4}$ (see calculated $\mathbf{J}$ values in Table 2).

For the two non-linear systems reported in this work (3 and 4), the same type of exchange interactions: (i) the first neighbour interaction trough the double $\mu$-OCR bridging ligand provides a relatively strong ferromagnetic coupling. (ii) The analysis of the calculated $\mathbf{J}$ values allows to establish a magnetostructural correlation with the MnII-O-MnIII angles (Fig. 10). Hence, an almost linear correlation is found between the calculated J values and the average the MnII-O-MnIII angle, larger angle values as those present in the non-linear complexes ( 3 and 4 ) result in stronger 
ferromagnetic coupling. It is worth noting that the calculated $\mathbf{J}$ values for $\mathbf{3}$ and $\mathbf{4}$ give slightly stronger ferromagnetic than the experimental ones, and similar overestimation of the $\mathrm{J}$ values were found by Hänninen et al.,20 who reported a similar correlation between $\mathbf{J}$ and the MnII-O-MnIII angle. (iii) The next-neighbour interactions are rather weak being the interaction between MnII centres slightly ferromagnetic while in 4 the MnII $\cdots$ MnIII is antiferromagnetic. (iv) In the 1D chain structure 4, the coupling between the [MnII2MnIII] units have been calculated and the exchange interaction through the $d c a$ bridging ligand is $-0.2 \mathrm{~cm}-1$ while the same $\mathrm{J}$ value is obtained for the contact through the double $\mathrm{O}-\mathrm{H} \cdots \mathrm{Cl}$ bridging ligand (see Fig. 9).

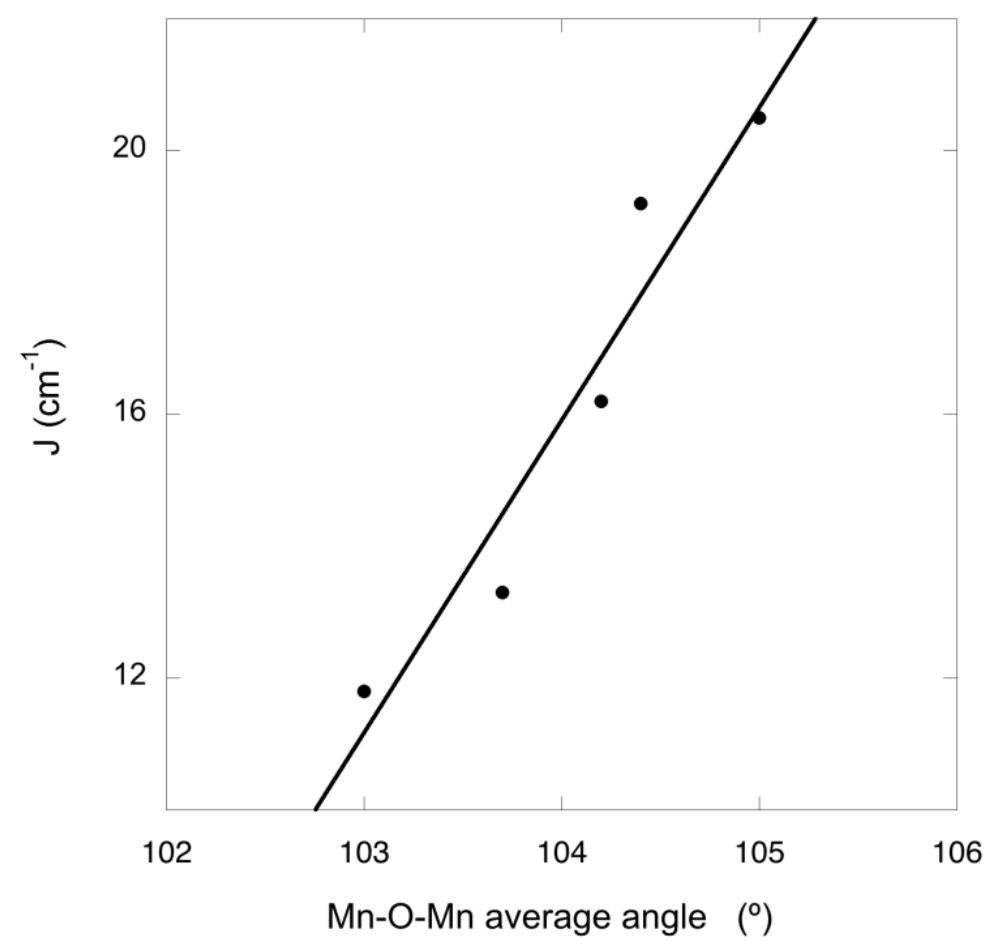

Fig. 10 Dependence of the DFT calculated J values with the average MnII-O-MnIII angle for the complexes $\mathbf{1}, \mathbf{3}$ and $\mathbf{4}$.

For the complex $\mathbf{3}$, the ground state $\mathrm{S}=14$ corresponds with the calculated high-spin configuration, thus, we can represent the spin population density corresponding to such state (see Fig. 11). Clearly 
it is possible to identify the almost spherical spin density shapes of the isotropic d5 MnII centres while those of the MniII cations are slightly distorted. The presence of one unpaired electron on each $\mathrm{d}$ orbital makes predominant the spin delocalization mechanism on the MnII centres predominant, due to the large mixing of the antibonding eg orbitals of the MnII cations with those of the coordinated atoms.25-26 However, the $\mathrm{dx}_{\mathrm{x} 2 \mathrm{y} 2}$ orbitals of the MnIII centers are empty, and spin polarization should be the predominant mechanism for the four equatorial atoms coordinated with these cations, giving a total negative spin density in these ligand atoms in the region closer to the MnIII cations (see blue lobes in Fig. 11).

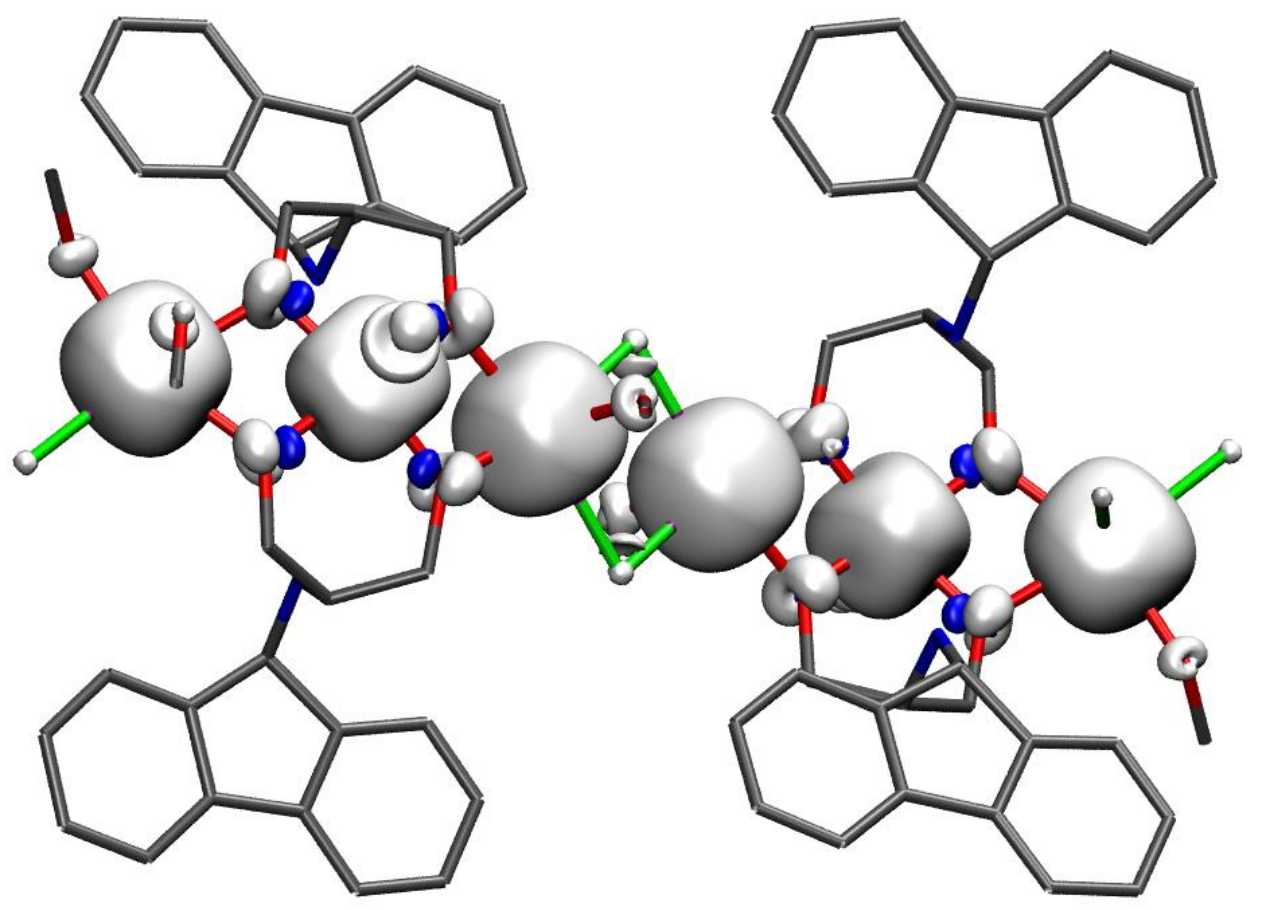

Fig. 11 Spin density map corresponding to $S=14$ high spin state of Mn6 complex 3, using a cut-off of $0.005 \mathrm{e} / \mathrm{bohr} 3$ white and blue regions that indicate positive and negative values, respectively.

Comparison with previously reported results for double-bridged alkoxo or phenoxo MnII $\cdots$ MnIII complexes20-24 are collected in Fig. 12 (see also Table S2). There is not a clear correlation with the angle due to the different nature of the ligands and there are more structural parameters that should 
play a subtle interplay to determine the magnetic properties. However, clearly the family of complexes reported in this work is that showing the strongest ferromagnetic coupling.

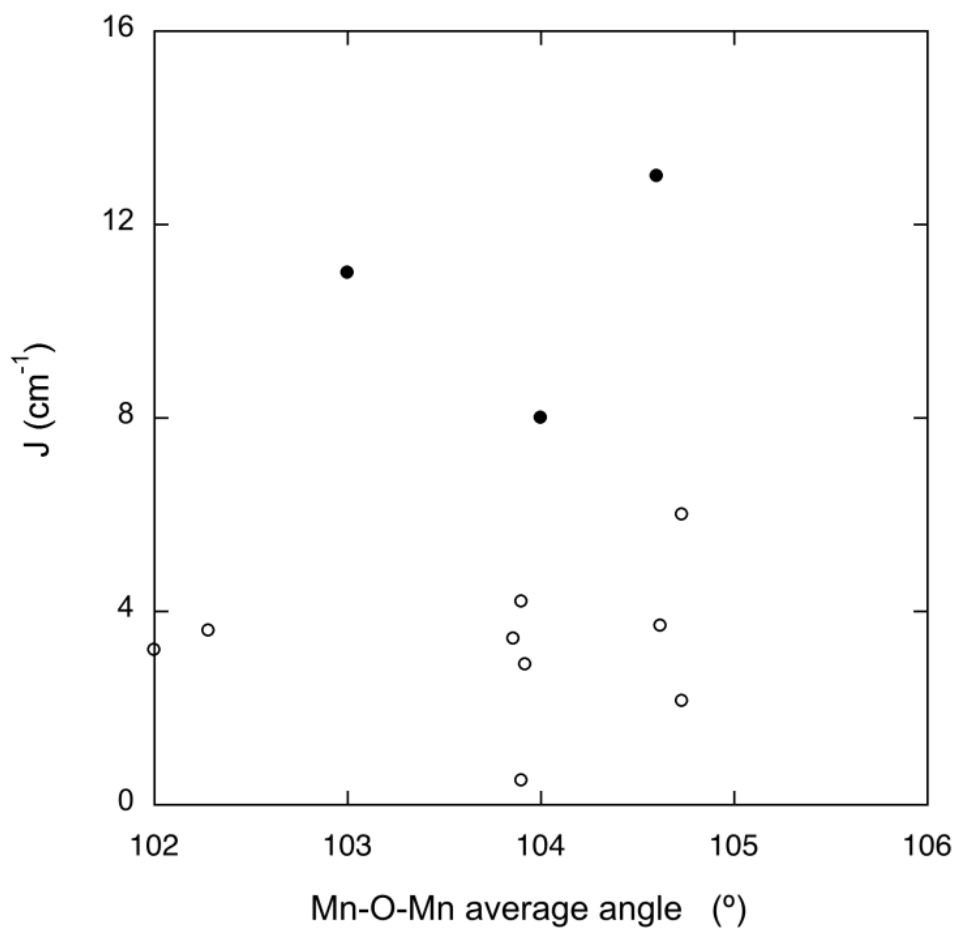

Fig. 12 Previously reported J values for double-bridged alkoxo or phenoxo MnII $\cdots$ MnIII complexes (white circles) and those of complexes 1, 3 and $\mathbf{4}$ (black circles).

\section{Conclusions}

Two new compounds have been synthesized and characterization of the magnetic properties was carried out, one [Mn4IIMn2III] system, containing two non-linear [MnII2MnIII] units and a 1D chain system with [MnıI2MnIII] units. The ferromagnetic exchange coupling experimentally found

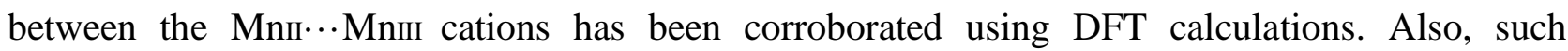
theoretical study allows to establish a magnetostructural correlation between the $\mathrm{J}$ values and the MnII-O-MnIII angles, being more ferromagnetic those systems with the largest angles. The 
comparison with previously reported double-bridged MnII $\cdots$ MnIII systems reveals that the family of compounds reported in this study exhibits, up to date, the strongest ferromagnetic coupling.

\section{Acknowledgements}

The research reported here was supported by the Spanish Ministerio de Economía y Competitividad (grant CTQ2015-64579-C3-1-P, MINECO/FEDER, UE). E.R. thanks Generalitat de Catalunya for an ICREA Academia award. J.C. gratefully acknowledges financial support from the Generalitat de Catalunya (7th program Beatriu de Pinos-Marie Curie cofund Fellowship, No. 2013 BP-B 00155). E.R. thankfully acknowledges the computer resources in the Consorci Serveis Universitaris de Catalunya (CSUC). W.G. and L.G. thank the National Natural Science Foundation of China $(21471066,21390394)$

\section{References}

1. R. Sessoli, D. Gatteschi, A. Caneschi and M. A. Novak, Nature, 1993, 365, 141.

2. G. Aromi and E. K. Brechin, Single-Molecule Magnets and Related Phenomena, 2006, 122, 1 .

3. D. Gatteschi and R. Sessoli, Angew. Chem. Int. Ed., 2003, 42, 268.

4. D. Gatteschi, R. Sessoli and J. Villain, Molecular Nanomagnets, Oxford University Press, Oxford, 2006.

5. A. M. Ako, I. J. Hewitt, V. Mereacre, R. Clérac, W. Wensdorfer, C. E. Anson and A. K. Powell, Angew. Chem. Int. Ed., 2006, 45, 4926.

6. E. Ruiz, T. Cauchy, J. Cano, R. Costa, J. Tercero and S. Alvarez, J. Am. Chem. Soc., 2008, 130, 7420.

7. Y. Jiang, L. Qin, G. Li, G. Abbas, Y. Cao, G. Wu, T. Han, Y.-Z. Zheng and S. Qiu, Dalton Trans 2015, 44, 5205.

8. E. Ruiz, P. Alemany, S. Alvarez and J. Cano, J. Am. Chem. Soc., 1997, 119, 1297.

9. $\quad$ E. Ruiz, J. Cano, S. Alvarez and P. Alemany, J. Comp. Chem., 1999, 20, 1391.

10. E. Ruiz, A. Rodríguez-Fortea, J. Cano, S. Alvarez and P. Alemany, J. Comp. Chem., 2003, 24, 982.

11. Gaussian 09 (release D.1) M. J. Frisch, G. W. Trucks, H. B. Schlegel, G. E. Scuseria, M. A. Robb, J. R. Cheeseman, G. Scalmani, V. Barone, B. Mennucci, G. A. Petersson, H. Nakatsuji, M. Caricato, X. Li, H. P. Hratchian, A. F. Izmaylov, J. Bloino, G. Zheng, J. L. Sonnenberg, M. Hada, M. Ehara, K. Toyota, R. Fukuda, J. Hasegawa, M. Ishida, T. Nakajima, Y. Honda, O. Kitao, H. Nakai, T. Vreven, J. Montgomery, J. A., J. E. Peralta, F. Ogliaro, M. Bearpark, J. J. Heyd, E. Brothers, K. N. Kudin, V. N. Staroverov, R. Kobayashi, J. Normand, K. Raghavachari, A. Rendell, J. C. Burant, S. S. Iyengar, J. Tomasi, M. Cossi, N. Rega, N. J. Millam, M. Klene, J. E. Knox, J. B. Cross, V. Bakken, C. 
Adamo, J. Jaramillo, R. Gomperts, R. E. Stratmann, O. Yazyev, A. J. Austin, R. Cammi, C. Pomelli, J. W. Ochterski, R. L. Martin, K. Morokuma, V. G. Zakrzewski, G. A. Voth, P. Salvador, J. J. Dannenberg, S. Dapprich, A. D. Daniels, Ö. Farkas, J. B. Foresman, J. V. Ortiz, J. Cioslowski and D. J. Fox, Pittsburgh, PA, 2003.

12. A. D. Becke, J. Chem. Phys., 1993, 98, 5648.

13. A. Schafer, C. Huber and R. Ahlrichs, J. Chem. Phys., 1994, 100, 5829.

14. D. Aravena, D. Venegas-Yazigi and E. Ruiz, Scient. Rep., 2016, 6, 23847.

15. S. Gómez-Coca and E. Ruiz, Magnetochemistry, 2015, 1, 62.

16. X.-Y. Wang, L. Wang, Z.-M. Wang, G. Su and S. Gao, Chem. Mater., 2005, 17, 6369.

17. B. E. Myers, L. Berger and J. Friedberg, J. Appl. Phys., 1969, 40, 1149.

18. C. J. O'Connor, Prog. Inorg. Chem., 1969, 29, 203.

19. J. Huang, G. Wu, J. Bai, Y. Jiang, G. Li, S. Qiu and R. Clérac, Inorg. Chem., 2013, 52, 11051.

20. M. M. Hanninen, J. Valivaara, A. J. Mota, E. Colacio, F. Lloret and R. Sillanpaa, Inorg. Chem., 2013, 52, 2228.

21. A. Yoshino, T. Miyagi, E. Asato, M. Mikuriya, Y. Sakata, K. Sugiura, K. Iwasaki, S. Hino and D. Hino, Chem. Commun. 2000, 1475.

22. R. T. W. Scott, S. Parsons, M. Murugesu, W. Wernsdorfer, G. Christou and E. K. Brechin, Chem. Commun., 2005, 2083.

23. M. Hirotsu, M. Kojima, W. Mori and Y. Yoshikawa, Bull. Chem. Soc. Jpn., 1998, 71, 2873.

24. A. Gelasco, M. L. Kirk, J. W. Kampf and V. L. Pecoraro, Inorg. Chem., 1997, 36, 1829.

25. J. Cano, E. Ruiz, S. Alvarez and M. Verdaguer, Comments on Inorg. Chem., 1998, $20,27$.

26. E. Ruiz, J. Cirera and S. Alvarez, Coord. Chem. Rev., 2005, 249, 2649. 